\title{
ZNACZENIE POCZAJOWSKICH DRUKÓW O CHARAKTERZE RELIGIJNYM DLA POZNANIA ŻYWEGO JEZZYKA RUSKOJĘZYCZNEJ SPOŁECZNOŚCI UNICKIEJ DAWNEJ RZECZYPOSPOLITEJ
}

JOANNA GETKA

Uniwersytet Warszawski

\begin{abstract}
THE SIGNIFICANCE OF POCHAIV RELIGIOUS PRINTINGS FOR THE UNDERSTANDING OF THE SPOKEN RUTHENIAN LANGUAGE OF THE RUTHENIAN GREEK CATHOLIC CHURCH COMMUNITY. The purpose of this article is to present the role of religious texts for the understanding of the spoken Ruthenian language in the former Commonwealth of the Two Nations (Rzeczpospolita). The books published by the Basilian printing house in Pochaiv during the $18^{\text {th }}$ century reveal the features of the common Ukrainian language (the approximation of the articulation of [i] and $[y],[u]$ and $[y]$, the hardening of $[t]$ and $[d]$ ), which support the thesis that it is a testimony of the state of the Ukrainian language of the $18^{\text {th }}$ century.
\end{abstract}

Keywords: basilians printings, $18^{\text {th }}$ century, ruska mova, Ukrainian language, Ukrainian culture

1. Celem artykułu jest ukazanie znaczenia badania literatury religijnej jako źródła badań żywego języka. Teksty o charakterze religijnym bywają bowiem z różnych względów (głównie wskutek przeświadczenia o utrzymywaniu się w nich skostniałych norm języka cerkiewnego) często pomijane w opisach lingwistycznych.

Szczegółowe badanie języka wybranych tekstów o charakterze religijnym wyekscerpowanych z wydanych w drukarni poczajowskiej starodruków prowadzą do sformułowania tezy, że ze względu na widoczne w tych tekstach cechy językowe, mające charakter upowszechniających się tendencji należy je traktować jako pełnoprawne źródło badań. Szczególnie wyraźnie odzwierciedlone są w zgromadzonym materiale językowym między innymi cechy fonetyczne, dlatego też niniejsze opracowanie poświęcone będzie przede wszystkim ich analizie.

Występowanie w analizowanych tekstach uzusowej (niekodyfikowanej gramatyką) normy językowej prowadzi do pytania, o związek języka tych tekstów z uzusem prostej mowy funkcjonującej na ziemiach ukraińskich w XVI-XVII wieku oraz - z drugiej strony 
- z normą współczesnego języka ukraińskiego. Wymusza to z kolei postawienie kolejnej tezy badawczej na temat nieprzerwanej ciągłości procesu tworzenia się normy ukraińskiego języka literackiego, którego cechą było stopniowe nasiąkanie cechami żywego języka, co w efekcie doprowadziło do wytworzenia się współczesnego języka literackiego, opartego - zgodnie z przyjętymi aksjomatami - o język ludowy, tj. potoczny.

2. Źródłem do badań w ramach tego artykułu są teksty o charakterze religijnym wydane w prostej mowie.

Kwestia prostej mowy jest mimo prowadzonej wiele lat dyskusji na temat jej powstania, charakteru, funkcji, zasięgu występowania i kręgów użytkowników ${ }^{1}$ jest nadal przedmiotem sporów naukowych. Nie będzie jednak nieprawdziwym uogólnione stwierdzenie (i w takim ujęciu będzie ona pojmowana w poniższych rozważaniach), iż była ona potocznym i literackim językiem przodków dzisiejszych Ukraińców i Białorusinów. Stanowiła zarazem alternatywę dla polszczyzny (system graficzny) i cerkiewszczyzny (liczne polonizmy).

Prosta mowa stała się oficjalnym językiem tekstów religijnych po Synodzie Zamojskim (1720) (Synod prowincjalny 1785: 43, Cubrzynska-Leonarczyk 1993: 241). Spowodowane to było wieloma czynnikami, wśród których dwa wydają się dominujące. Jest oczywiste, że jednym z nich była przyczyna utylitarna - ułatwienie zrozumienia przekazu przez wiernych. Język ruski - prosta mowa był - co podkreśla Iwan Ohijenko - powszechnym środkiem komunikacji na ziemiach koronnych, wykorzystywanym nawet w kontaktach domowych w niektórych rodach książęcych (Ohienko 1995: 95). Dodatkowo, w wyniku zróżnicowania

1 O ile polscy slawiści określili ją po prostu jako język pisany odrębny od cerkiewszczyny i polszczyzny przez nasycenie fonetyki i słownictwa elementami żywego języka ludowego (Splawinski \& Zwolinski \& Hrabec 1956: 30, Brückner 1958: 358) to współcześnie, pojawiają się teorie, wedle których ruska i prosta mowa stanowią warianty jednego ogólnego języka zachodnioruskiego. Według Władimira Miakiszewa (Miakiszew 20o8: 38-39) na przykład, określenie język ruski utworzone zostało dla odróżnienia go od polszczyzny, prosta mowa zaś stała w opozycji do cerkiewszczyzny. Teorie uczonych ukraińskich (Shevelov 2002: 719) zakładają, że prosta mowa stanowi kontynuacjęjęzyka ruskiego i była używana na ziemiach ukraińskich po XVI w., co uzupełniają inni badacze, rozciągając zasięg jej występowania na ziemie białorusko-ukraińskie (Mozer 2002: 211, Humeckaya 1965: 44, Morita 2002: 147-153). Prosta mowa jest w tym ujęciu tworem ponadregionalnym, wspólnym dla Białorusinów i Ukraińców. Dodatkowo pojawiają się tezy o różnych funkcjach języków: o ile prosta mowa miała być językiem literatury, język ruski był językiem kancelarii i aktów prawnych (Mozer 2002: 27-34). Szerzej na temat dyskusji o prostej mowie: Getka, J. „Język Nauk Parafialnych (1794) - ukraiński wariant prostej mowy końca XVIII wieku.” Warszawa, 2012, 17-27; Getka, J. „Białoruski? Ukraiński? Uwagi o metodologii klasyfikacji źródeł powstałych na ziemiach białoruskich i ukraińskich w XIV-XVII ww.” Studia Interkulturowe Europy Środkowo-Wschodniej, no 4 (2010): 50-67; Getka, J. „Białoruski i ukraiński wariant prostej mowy XVIII wieku czy białoruska i ukraińska prosta mowa XVIII wieku? (na materiale ruskojęzycznych teologii moralnych z Supraśla, Uniowa i Poczajowa).” W: Citko, L., red. Języki ruskie w rozwoju historycznym i kontaktach z polszczyzną. Białystok, 2018, 99-125. 
dialektalnego obszaru języków wschodniosłowiańskich, cerkiewnosłowiański język liturgiczny stał się z biegiem czasu niezrozumiały nie tylko dla parafian, ale także i duchowieństwa, co podkreślają ówcześni autorzy. W przedmowie do przekładu Ewangelii Wasyl Ciapiński twierdzi, że duchowni najmniej (cerkiewny) rozumieja, nawet się go nie ucza (Bruckner 1958: 359)².

Druga motywacja sięgnięcia do prostej mowy związana była z sytuacją społeczno-kulturową. Kościół unicki, działający na terytorium kanonicznym prawosławia dążył do poszerzenia kręgu odbiorców. W XVIII wieku, wobec zbliżającej się klęski Rzeczypospolitej i związanego z nią realnego zagrożenia dla Kościoła unickiego (które dokonało się ostatecznie w aktach kasacji unii w Imperium Rosyjskim 1836 i Królestwie Polskim - 1875 roku), potrzeba przekonania do unickiej wizji wyznania była szczególnie silna. Na stworzenie wspólnej, silnej tożsamości Rusinów-unitów wpływać miały wspólny, własny, odrębny język, wspólna unicka obrazowość religijna, poczucie wspólnoty historycznej na poziomie lokalnym. Kształtowanie wymienionych elementów tożsamości unickiej wyraźnie zauważalne jest w drukarstwie bazyliańskim³. W efekcie, druk w prostej mowie stanowił więc zarazem cel misji bazyliańskiej - zakonnicy dbali o jej upowszechnienie o czym świadczą przedmowy do wydanych przez nich tekstów o charakterze świeckim, które miały służyć za podręczniki do nauki czytania / elementarze na wzór katechizmów (Książka lekarstw końskich 1788: 5-6). Dlatego też, niezależnie od pewnych problemów jakie nastręczał druk w niekodyfikowanym języku, zakonnicy konsekwentnie kontynuowali tradycję druku w prostej mowie ${ }^{4}$. W tym ujęciu charakterystyka prostej mowy - funkcjonowanie jej w opozycji do polszczyzny i cerkiewszczyzny, znakomicie uzupełniała misję społeczno-kulturową bazylianów polegającą na wytworzeniu swoistej przestrzeni kulturowej (Slavia Unita) między światami Slavia Romana i Slavia Orthodoxa.

2 Z kolei w przedmowie do wydanego w Supraślu w 1722 roku słownika (Лексикон сиреч словесник славенский, имеющ в себе словеса первее Славенския, Азбучныя, посем же Польския) stwierdzono, że dany leksykon wydrukowano z myślą o kandydatach do stanu duchownego Cerkwi Unickiej, gdyż ledwo co setny rozumie język cerkiewnosłowiański, co więcej - wielu spośród jerejew nie wie co czyta! (Jaroszewicz-Pieresławcew 2003: 191).

3 Por. Getka, J. U progu modernizacji. Ruskojęzyczne drukarstwo bazyliańskie XVIII wieku. Warszawa, 2017; Getka, J. „Василіянські руські друковані видання релігійного характеру (Почаїв, XVIII сторіччя) як джерело для дослідження української культури.” W: Культуротворча місія Почаївського василіянського монастиря. Упоряд. архиєп. Ігор Ісіченко. Харків: Акта, 2018, 85-99.

4 Zauważając wspomniane trudności, ale ze względu na zapotrzebowanie odbiorców redaktorzy bazyliańscy decydowali по силь моей начну писати Русскимъ Языкомъ (бо еже множайшымъ оу насъ оугодну сему быти). W wstępie do swojej pracy Fiodor Basarabski (1771: 14) podkreśla przy tym, że innym doświadczeniem jest wykładanie i nauczanie wiernych po rusku, a zupełnie innym spisanie swoich myśli w tym języku. 
3. Szczególną rolę w propagowaniu prostej mowy miała drukarnia w Poczajowie, której wydania stanowią źródło do badań w ramach niniejszego artykułu.

Liczbą publikowanych tam książek czcionką cyrylicką wydanych w języku cerkiewnosłowiańskim i (co istotne z punktu widzenia niniejszego opracowania) w języku ruskim wyróżnia się ona nie tylko na tle innych drukarni bazyliańskich (w Wilnie, Supraślu, Mińsku, Poczajowie, Uniowie i Lwowie), ale i ogółu typografii XVIII wieku na ziemiach ukraińskich5.

W kontekście analizy tekstów o charakterze religijnym warto podkreślić, że w języku tym zostały opublikowane nie tylko pełne odrębne teksty zwarte; tekst ruskojęzyczny występuje również w postaci krótszych bądź dłuższych fragmentów w tekstach wydanych z założenia w innych językach (cerkiewnosłowiańskim, łacińskim bądź polskim). Odrębną grupę - ze względu na specyfikę języka (specyfika stylistyki tekstu wierszowanego) stanowią pieśni religijne w prostej mowie. Do tekstów o charakterze religijnym można zaliczyć również dokumenty, związane z funkcjonowaniem kościoła greckiego. Liczbę bazyliańskich wydań ruskojęzycznych ilustruje poniższa tabela:

Tabela 1. Druki ruskojęzyczne na tle druków wydanych czcionką cyrylicką w Poczajowie oraz innych typografiach bazyliańskich. ${ }^{6}$

\begin{tabular}{|c|c|c|c|}
\hline DRUKARNIA & & DRUKI & LICZBA DRUKÓW \\
\hline \multirow{3}{*}{ poczajowska } & \multicolumn{2}{|c|}{ wydane cyrylicą } & (329) \\
\hline & \multirow[t]{2}{*}{ w tym: } & ruskie & (25) \\
\hline & & fragmenty & (15) \\
\hline \multirow{3}{*}{ wileńska } & \multicolumn{2}{|c|}{ wydane cyrylicą } & (18) \\
\hline & \multirow[t]{2}{*}{ w tym: } & ruskie & (0) \\
\hline & & fragmenty & (0) \\
\hline \multirow{3}{*}{ supraska } & \multicolumn{2}{|c|}{ wydane cyrylicą } & (109) \\
\hline & \multirow{2}{*}{ w tym: } & ruskie & (3) \\
\hline & & fragmenty & (3) \\
\hline
\end{tabular}

5 Księgi cyrylickie stanowiły ponad 54\% wszystkich druków wydanych w drukarni bazylianów w Poczajowie. Wydania polskojęzyczne stanowiły ok. 30\% oferty wydawniczej tej placówki. W drukarniach w Wilnie i Supraślu natomiast, wydania polskojęzyczne obejmowały około 70\% ogółu publikacji (Getka, J. Polskojęzyczne druki bazyliańskie (XVIII wiek). Warszawa, 2013, s. 248).

6 Lista tytułów ruskojęzycznych zamieszczona jest w aneksach do książki: Getka, J. U progu modernizacji. Ruskojęzyczne drukarstwo bazyliańskie XVIII wieku. Warszawa, 2017: 280-29o. 


\begin{tabular}{|l|l|l|l|}
\hline \multirow{2}{*}{$\begin{array}{l}\text { wydane cyrylicą } \\
\text { mińska }\end{array}$} & w tym: & ruskie & $(0)$ \\
\hline & fragmenty & $(0)$ \\
\hline \multirow{3}{*}{ uniowska } & wydane cyrylicą & $(0)$ \\
\hline \multirow{3}{*}{ lwowska } & w tym: & ruskie & $(31)$ \\
\hline & fragmenty & $(4)$ \\
\hline \multirow{2}{*}{ wydane cyrylicą } & ruskie & $(3)$ \\
\hline & w tym: & fragmenty & $(2)$ \\
\hline
\end{tabular}

Wśród odrębnych wydań można wymienić kilka tytułów, z których każdy był kilkukrotnie przedrukowany. Najbardziej potrzebną i popularną okazała się teologia moralna (Bohoslovija nravouchytel'naja 1751, Bohoslovija nravouchytel'naja 1756, Bohoslovija nravouchytel'naja 1787, która stanowiła przedruki wcześniejszych wydań z Supraśla i Uniowa (Sobranije 1722, Sobranije 1732, Pouchenije o svyatykh taynakh 1745). Ku pożytkowi czytających i słuchających ukazywały się również ewangeliarze na niedziele zwykłe i świąteczne (Simja slova 1772, Simja slova 1781, Nauky parokhialnija 1792, Nauky parokhialnija 1794), ewangeliarze misjonarskie, w stosunku do ewangeliarzy zwykłych uzupełnione o dodatkowy wstęp do wybranego zagadnienia teologicznego (Slovo $k$ narodu kafolicheskomu 1765, Narodovishchanije 1768, Narodovishchanije 1778) i katechizmy (Ohlashenije 1788). Raz wydano tu podręcznik dogmatyczno-moralny Fiodora Basarabskiego (Basarabski 1771).

W języku ruskim ukazywały się także całe krótsze teksty umieszczone jako elementy większych wydań. Były wśród nich dokumenty (np. uchwała Synodu Brzeskiego z 1596 roku w zbiorze dokumentów Bullae et Brevia Summorum Pontificum Sacrarum Congregationum Decreta... Poczajów 1767), pieśni, publikowane pojedynczo jako dodatek do innych wydań czy wręcz jako odrębne wydania, czy poezja - np. wiersz Iwana Wieliczkowskiego Анна Ми Мати z Molitosłowa z 1755 roku (Molitoslov 1755: 270). Po rusku, jak już wspomniano, ukazywały się również drobne wstawki, fragmenty w tekstach pisanych z założenia językiem cerkiewnosłowiańskim. Takie elementy (modlitwy, zwroty, wskazania) pojawiają się w kolejnych wydaniach publikacji na temat obrzędu przyjęcia nowicjusza do stanu mniszego pt.: Посльдованіе постригу двою (Poslidovanije 1750, Poslidovanije 1793). Teksty przysiąg, rozmów z parochem pojawiały się w trebnikach, akatystarzach oraz w swoistym poradniku dla parochów, pt. Чинъ Іерейскаго наставленїя в пути въчныя жизни бользнующихъ (Chyn 1776). 
Dane te świadczą nie tylko o skali produkcji typografii poczajowskiej, ale zarazem o zapotrzebowaniu ówczesnych czytelników - odbiorców druków o charakterze religijnym wydanych w zakładach bazyliańskich. Co więcej - w sytuacji zauważalnego w XVIII wieku kryzysu w rozwoju piśmiennictwa w języku ukraińskim - rola kulturotwórcza tych tekstów nie polegała na zwykłej odpowiedzi na zapotrzebowanie czytelników, a na swoistej promocji języka mówionego poprzez aktywne wykorzystywanie go w kontaktach z wiernymi (co było zgodne z postanowieniem VI Kongregacji Generalnej bazylianów z 1636 roku, aby ojcowie i bracia nie inaczej głosili Słowo Boże jedno po rusku (Niec 1936: 148)) oraz pokazanie jego możliwości jako języka druków. W rezultacie prosta mowa, będąc jednym z języków wydań bazyliańskich, miała rangę języka równorzędnego uznanym już językom literackim (cerkiewszczyźnie czy polszczyźnie).

W tym ujęciu druki te nie tylko odzwierciedlają, ale zarazem kreują sytuację socjolingwistyczną na ziemiach ukraińskich7, stymulując zarazem rozwój kultury społeczności unickiej ${ }^{8}$. O sile oddziaływania tych tekstów świadczą ich liczne przedruki.

4. Analiza dorobku wydawniczego zakonników pokazuje, że teksty o charakterze religijnym odzwierciedlają prostą mowę w XVIII wieku w sposób wyraźny w stopniu typowym dla piśmiennictwa świeckiego.

W tekstach tych zaznaczone są ukraińskie cechy językowe, co przeczy przy okazji często stosowanej przez ówczesnych pisarzy tendencji do unifikacji języka swoich utworów i swoistej nadregionalności, tak, by czytelnicy mogli odczytać tekst zgodnie ze swoimi przyzwyczajeniami językowymi. Problem opisuje celnie A. Bułyka, konstatując: Dbając, by ich utwory były zrozumiałe przez wszystkich mieszkańców Wielkiego Księstwa Litewskiego, ówcześni pisarze starali się unikać zapisów, które mogłyby temu przeszkodzić. [...] Oprócz tego, starobiałoruscy i staroukraińscy pisarze często zmieniali miejsca zamieszkania, żyli więc, i tworzyli to na Białorusi, to na Ukrainie. Dlatego w swoich utworach mieszali czasem cechy obu języków (Bulyka 1970: 66-67).

Spostrzeżenia te nie mają zastosowania do analizowanych tekstów z prostej, wskazanej już wyżej przyczyny: drukarze poczajowscy byli zorientowani na czytelnika

7 Warto także podkreślić, że oddziaływanie drukarstwa bazyliańskiego wychodziło daleko poza obszar prawobrzeżnej Ukrainy. Jarosław Isajewicz zauważa, że drukowane przez zakonników pieśni i kolędy nowego typu musiały wywrzeć wpływ na późniejszych pisarzy, w tym także na twórczość najwybitniejszego ukraińskiego poety - Tarasa Szewczenki mimo to, że ziemie ukraińskie znajdowały się w końcu XVIII wieku w składzie różnych państw, to zjawiska kulturowe przenikały z jednej części do drugiej, a twórcy kultury mieli tego świadomość (Isajevych 1994: 173).

8 Por. Getka, J. U progu modernizacji. Ruskojęzyczne drukarstwo bazyliańskie XVIII wieku. Warszawa, 2017. 
posługującego się gwarami ukraińskimi, zaznaczali więc raczej te cechy językowe, które utożsamiane były z językiem ich odbiorców. W tekstach wyraźnie odzwierciedlano dystynktywne cechy języka ukraińskiego, m.in.: rozwój dawnego jać w [i], ikanie, zbliżenie artykulacji [i] i [y], zbliżenie artykulacji [u] i [y], stwardnienie [t] i [d]. Zauważalny w tekstach wpływ normy piśmiennictwa cerkiewnosłowiańskiego, jest uwarunkowany gatunkiem tekstów, ale również - jak uważają niektórzy badacze - w ogóle ukraiński wariant prostej mowy charakteryzuje większe nasycenie cerkiewizmami, niż białoruski jej wariant (nasycony polonizmami) ${ }^{9}$. Trzeba jednak podkreślić, że trzymanie się etymologicznego (normy cerkiewnosłowiańskiej) zapisu widoczne jest w tych miejscach, gdzie umożliwia to odzwierciedlenie ukraińskiego typu wymowy. Czytelnik musiał być w tym przypadku uzbrojony w pewne uzusowe zasady artykulacji określonych grafemów (np. wymowę $n$ jako [i]).

Czasem jednak i te informacje były zbędne. Typowe ukraińskie ikanie, zwłaszcza w wyrazach pochodzenia obcego zaznaczano przez zastosowanie grafemów $\ddot{i}, i$ w miejscu oczekiwanego [e], nр.: ажібы [pol. аżeby], ущирбку [ukr. шкода, втрата, збиток, pol. uszczerbek]. Nie mniej, również zapisy pośrednie, z wykorzystaniem $n \mathrm{w}$ miejscu etymologicznych [ $\left.{ }^{*} \mathrm{o}\right],\left[{ }^{*} \mathrm{e}\right] \mathrm{w}$ sylabach nowozamkniętych czytano jako [i]: день и нпчь, на помпчь, розбъйники, również we fleksji: неукпвъ, учнпвъ, простакпвъ, збувало уломковъ дванадесять кошпвъ.

Ukraińskie zlanie się [y] (szereg tylny) i [i] (szereg przedni) w jeden dźwięk (szereg przedni, wysoki), ukr. [и] oddawane jest za pomocą zapisów: a) liter $i, \ddot{l}$ w miejscu etymologicznego [y]; b) litery ы w miejscu etymologicznego [i]. Takie dublety ortograficzne notowane są we wszystkich pozycjach niezależnie od pochodzenia i budowy morfologicznej wyrazów: w przedrostkach, morfemach rdzennych czy fleksjach: биты, мпты, абыся виражала, добиваты, замикаты, вимислилы, билы купленїи, оурядамы церковнымы, которихъ лютехъ, лугъ не барзо готованйй.

Zapis bl w miejscu etymologicznego [i] świadczy przy okazji o depalatalizacji poprzedniej spółgłoski. Występujące w tekstach zapisy odzwierciedlają tzw. wtórne stwardnienie [d]: исповпды потребовалъ, на остатней сповпды, występowanie twardego [t] zarówno w formach infinitywów na -ты: святитыся, арендоваты, браты, взяты, чиниты, jak i w końcówkach innych części mowy: ненависты, по смерты, часты, утрачоной невинносты, obecność twardych [b]: одробыни, [1]: отбыралы, якобы оны вимислилы, абы вся своя мыслы, [m]: подъ особамы, ногамы, щедротамы, [n]: казны наноститы, въ отхланы, въ дны святыя, [v]: хлпбовы, тому сакраментовы i - w końcu twardych [k],

9 Uspenskij 1994: 68; Getka, J. Język „Nauk Parafialnych” (1794) - ukraiński wariant prostej mowy końca XVIII wieku. Warszawa, 2012, s. 22. 
[g], [х]: бобкы, олпйкы, зневагы, пихы. W tych ostatnich nie należy doszukiwać się wpływu normy cerkiewnosłowiańskiej; występują one bowiem w wyrazach różnego pochodzenia.

Rozpodobnienie spółgłosek m.in. w zaimku pytajnym * w zapisach: щo, gdzie grafem щ należy czytać jako [šč], również ma charakter ukraiński. Ten sam grafem stosowany jest dla zapisu wyrazów polskich: въ щегульности. Na tej podstawie można wnioskować o ukraińskiej artykulacji wyrazów: що, нащожъ, нещо, щоденне itd.

Nieco rzadziej rozpodobnienie odzwierciedlone jest również $\mathrm{w}$ grupie ${ }^{*} k b t>x t$ : zaimek osobowy pojawia się w postaci: xmo.

W tekstach, zgodnie z tradycją piśmiennictwa staroukraińskiego zaznaczona jest również typowa ukraińska asymilacja spółgłosek bezdźwięcznych przed spółgłoskami bezdźwięcznymi (Mojsijenko 20o6: 11): безконечне, од sлого, од того часу.

Odzwierciedlają one również typowy ukraiński prefiks vid-: впдпускати, въдпустили (równolegle - zapisy tradycyjne przedrostka w postaci ot-: omnycкaeme, omдатu, отповидпвъ i in.

O ukraińskim charakterze wzdłużenia spółgłosek, wobec braku tradycji zapisu obok siebie dwóch takich samych spółgłosek świadczą dane morfologiczne, mianowicie obecność końcówki -‘a (graficznie -я) w Nom. i Acc. sg.: чрез неушанованя, засвъдчитъ сумленя, само досвпдченя, мпты стараня, збожа молоти въ млинахъ, казаня правиты, импючи теды оулатвпня достаточное, волося віпадаетъ.

Co szczególnie istotne: biorąc pod uwagę brak tradycji oraz fakt, że nawet autor Eneidy nie oznaczał wzdłużenia (Buryachok 1969: 76), zabiegi zastosowane przez bazylianów, którzy zarówno w tekstach o charakterze religijnym (за отпущеніе карання дочеснаго), jak i świeckim (тепрпентилля, спллю, зюлля) stosowali zapisy dwóch sąsiadujących spółgłosek należy uznać za bardzo śmiałe.

W sposób zbliżony do współcześnie przyjętego w ortografii ukraińskiej (za pomocą grafemu в odzwierciedlone jest przejście [ ${ }^{*}$ l] > [в (u-niezgłoskotwórcze)] w dawnych grupach TъlT, TъlT i w imiesłowach przysłówkowych rodzaju męskiego czasu przeszłego: воду вливъ въ кильхъ, помиливъся, мовчавъ, продовживъ, довгъ.

Analogicznie - zgodnie z normami współczesnej ukraińszczyzny wybuchowe [g] oddawane jest za pomocą odrębnego grafemu - Г: вагу, Гарнецъ Грунтъ, Гвалтовный, także w polonizmach: фигура, въ щеГульности, плюГавства. Litera г oznacza więc w tekstach dźwięk frykatywny $[\gamma]$, co potwierdzają zapisy polonizmów, w których grafem z oddaje polskie tylnojęzykowe $[\gamma]$, a nawet $[\mathrm{x}]$ oznaczane w języku polskim przez literę $h$ i dygraf ch: въ панствъ Гишпанскомъ, погамовану, глухіи слугъ, хромїи ногъ владпнїе отбирали.

Warto wspomnieć i o innych typowych dla języka ukraińskiego cechach fonetycznych i morfonologicznych: powszechnym jest na przykład użycie form czasownikowych 
3 os. sing. i pl. czasu przeszłego oraz bezokolicznika z formantem -ov-, który od XV stulecia wypierał sufiks -iv, obecny dziś w języku rosyjskim (Ohienko 2011: 279). O powszechności użycia tego typu form, przekazujących cechę długotrwałą lub powtarzalną, świadczą dokumenty z Wołynia, Naddnieprza i Lewobrzeżnej Ukrainy z XVII-XVIII wieku, a później także utwory Iwana Niekraszewicza, Iwana Kotlarewskiego czy Tarasa Szewczenki (Strelchuk 1990: 17): отправовати, сполковати, оказовати, оплаковавъ. W pozycji nieakcentowanej przyjmuje on w języku ukraińskim formę -uv-: була, забувавъ, жалувалибысмо, працювавъ, шанувати повинен примушувати, незабували, добувати.

Ukraiński charakter ma również wymiana głosek w odmianie czasowników z tematem zakończonym na spółgłoskę wargową: w formach 3 os. pl. dzięki tendencji do wyrównania tematów, przed końcówką pojawia się wstawne -l: доступлят', u czasowników z tematem infinitiwu zakończonym na $[\mathrm{g}]$ zaś, zachodzi alternacja $[\mathrm{g}]>[\check{z}]$ : Mapia i Iocuф допоможутъ вамъ.

\section{Zakończenie}

Zaproponowana w artykule analiza ruskojęzycznego drukarstwa bazyliańskiego o charakterze religijnym ukazuje znaczenie tych tekstów w badaniach nad rozwojem języka ukraińskiego. Prowadzi ona do kilku wniosków:

- weryfikacji poglądów na temat roli piśmiennictwa religijnego w poznaniu żywego języka XVIII wieku;

- weryfikacji poglądów na temat funkcjonowania prostej mowy w XVIII wieku. Język ten funkcjonował nadal jako język druków różnych gatunków literackich i różnych stylów (w niniejszym artykule przyjrzano się tekstom o charakterze religijnym, które można zaliczyć do dawnych: średniego stylu - kazania i wysokiego - literatura piękna - wiersze, pieśni). Nabierał on - niezależnie od przynależności gatunkowej coraz więcej elementów języka mówionego, co świadczy o jego stopniowym zbliżaniu się do normy języka współczesnego, którego główną zasadą jest zbieżność z językiem mówionym wyraźnie zauważalna na poziomie ortograficznym (odejście od zapisu morfologicznego na rzecz fonetycznego);

- potwierdzeniu roli poczajowskiego ośrodka drukarskiego w kreowaniu sytuacji socjolingwistycznej na ziemiach ukraińskich (dzięki szerokiemu rozprzestrzenieniu tekstów, również poza obszar dzisiejszej Ukrainy Prawobrzeżnej). Dzięki konsekwentnemu drukowi (przypomnijmy - analizowane teksty o charakterze religijnym ukazywały się do końca XVIII wieku) w prostej mowie zwiększał się krąg wiernych, co było priorytetowym celem misji bazylianów. Jednocześnie jednak rósł prestiż języka wiernych, który na równi z uznanymi językami liturgii - jak cerkiewnosłowiański czy łacina - stawał się językiem Kościoła. 


\section{BIBLIOGRAFIA}

Basarabskyj 1771: Basarabskyj, Fedir. Pysmena si jest Nachatki dogmato-nravouchytelnyja bohoslovii. Pochayiv, 1771. [In prosta mova: Басарабський, Федір. Писмена си єсть Начатки догматонравоучителныя богословіи. Росzajów, 1771.]

Bohoslovija nravouchytel'naja 1751: Bohoslovija nravouchytel'naja... Pochayiv, 1751. [In prosta mova: Богословіа нравоучителная... [Poczajów], 1751.]

Bohoslovija nravouchytel'naja 1756: Bohoslovija nravouchytel'naja... Pochayiv, 1756. [In prosta mova: Богословіа нравоучителная... [Poczajów], 1756.]

Bohoslovija nravouchytel'naja 1787: Bohoslovija nravouchytel'naja... Pochayiv, 1787. [In prosta mova: Богословіа нравоучителная... [Poczajów], 1787.]

Bruckner 1958: Brückner, Aleksander. History of Polish Culture, vol. 2. Warsaw: Ksiazka i Wiedza, 1958. [In Polish: Brückner, Aleksander. Dzieje kultury polskiej, t. 2. Warszawa: Książka i Wiedza, 1958.]

Bulyka 1970: Bulyka, Aleksandr. Development of a Spelling System of the Old Belarusian Language. Minsk: Navuka i Tehnika, 197o. [In Belarusian: Булыка, Аляксандр М. Развіццё арфаграфічнай сістэмы старабеларускай мовы. Мінск: Навука і тэхніка, 1970.]

Buryachok 1969: Buryachok, Andriy. "I. P. Kotlyarevsky in the History of the Ukrainian Literary Language." Radyanske Literaturoznavstvo, no 9 (1969): 71-76. [In Ukrainian: Бурячок, Андрій. „І. П. Котляревський в історії української літературної мови.” Радянське літературознавство, nо 9 (1969): 71-76.]

Chyn 1776: Chyn ierejskaho nastavljenija... Pochayiv, 1776. [In prosta mova: Чинъ Іерейскаго наставленїя... [Poczajów], 1776.]

Cubrzynska-Leonarczyk 1993: Cubrzynska-Leonarczyk, Maria. "Uniate Typography in Suprasl as a Centre of Cyrillic Printing." In Rusek, J. et al., eds. The Oldest Church Slavonic Prints and Literary Tradition, 237-247. Cracow: Institute of Slavic Philology, 1993. [In Polish: Cubrzyńska-Leonarczyk, Maria. „Unicka oficyna supraska jako ośrodek drukarstwa cyrylickiego.” W: Rusek, J. et al., red. Najstarsze druki cerkiewnostowiańskie i ich stosunek do tradycji piśmienniczej, 237-247. Kraków: Instytut Filologii Słowiańskiej, 1993.]

Isajevych 1994: Isaevich, Yaroslav. "Fundamentals of Religious Life and Culture in Ukraine (by the end of the XVIII century)." In Kloczowski, J., ed. Belarus, Lithuania, Poland, Ukraine. The Foundations of Historical and Cultural Traditions in East Central Europe, 155-174. International Conference, Rome, 28 April - 6 May 1990. Lublin: Institute of East Central Europe, 1994. [In Ukrainian: Ісаєвич, Ярослав. „Основи релігійного життя і культури на Україні (до кінця XVIII cm.).“ In Kłoczowski, J., ed. Belarus, Lithuania, Poland, Ukraine. The Foundations of Historical and Cultural Traditions in East Central Europe, 155-174. International Conference, Rome, 28 April - 6 May 199o. Lublin: Instytut Europy Środkowo-Wschodniej, 1994]. 
Ksiazka lekarstw konskich 1788: Book of horse medicines and ways rescue in Sickness, Cattle, Sheep, E c. in Basilians Typography in 1788 in Poczayiv. [In Polish and Ukrainian: Książka lekarstw końskich oraz sposoby ratowania w Chorobach, Bydła, Owiec, E c. w Typografi i WW. OO. Bazylianow za Przywileiem J. K. Mci. 1788 R. w Poczaiowie. // Книжиця для господарства, указующая, якъ ратовати въ хоробахъ всякую скотину, то есть: конп, воли, впвцъь, козы, свинп, якъ бплити полотно, якъ боронити пашнпот саранчи, як ратовати ся от джуми, якъ губити гуселницю от капусти, якъ ловити рибу, якъ губити мыши и щурп, якъ ратовати скажени собаки, якъ ратовати людій, которихъ собаки скаженіи покусали, якъ ратовати человпка, который не въ давномъ времени зъ ума зыйдетъ.]

Lehr-Splawinski \& Zwolinski \& Hrabec 1956: Lehr-Spławinski, Tadeusz \& Zwolinski, Przemyslaw \& Hrabec, Stefan. A Short History of the Ukrainian Language. Warsaw: PWN, 1956. [In Polish: Lehr-Spławiński, Tadeusz \& Zwoliński, Przemysław \& Hrabec, Stefan. Dzieje języka ukraińskiego w zarysie. Warszawa: PWN, 1956].

Miakiszew 2008: Miakiszew, Vladimir. The language of the Lithuanian Statute of 1588. Cracow: Lexis, 2008. [In Polish: Miakiszew, Władimir. Język Statutu Litewskiego 1588 r. Kraków: Lexis, 2008.]

Morita 2002: Morita, Koji. "The Connection between Prosta Mova in the Old Eastern Borderlands ahd Prosta Mova in the Grand Duchy of Lithuania. Terminological Notes." In Abramowicz, Z., ed. Multilingualism and Multiculturalism in the Polish - East Slavic Borderlands. Studia Slawistyczne, no 3, 147-153. University of Bialystok Press, 2002. [In Polish: Morita, Koji. „Związek prostej mowy na dawnych Kresach Wschodnich z prostą mową w Wielkim Księstwie Litewskim. Uwagi terminologiczne." W: Abramowicz, Z., red. Wielojęzyczność i wielokulturowość na pograniczu polskowschodniosłowiańskim. Studia Slawistyczne, nr 3, 147-153. Białystok: Uniwersytet w Białymstoku, 2002.]

Moser 2002: Moser, Michael. "What is prosta mova?" Studia Slavica Hungaricae, no 47 (2002): 3-4, 221-26o. [In Ukrainian: Мозер, Міхаель. „Что такое простая мова?“ Studia Slavica Hungaricae, no 47 (2002): 3-4, 221-26o.]

Mojsijenko 20o6: Mojsijenko, Viktor. "Northern dialects of Ukrainian language in XVI-XVII cc. Phonetics.” DSc dissertation. Zhytomyr State University of Ivan Franko, 20o6. [In Ukrainian: Мойсієнко, Виктор. „Північне наріччя української мови в XVI-XVII ст. Фонетика.“ Дисертація. Житомирський державний університет імені Івана Франка, 2006.]

Narodovishchanije 1768: Narodovishchanije... Pochayiv, 1768. [In prosta mova: Народовъщаніе... [Poczajów], 1768.]

Narodovishchanije 1778: Narodovishchanije... Pochayiv, 1778. [In prosta mova: Народовпщаніе... [Poczajów], 1778.]

Nauky Paroxial'nija 1794: Nauky Paroxial'nija... Pochayiv, 1794. [In prosta mova: Науки парохіалнія... [Poczajów], 1794.]

Niec 1936: Niec, Julian. "Print Houses in Volhynia." Oriens, vol. IV (1936): 147-150. [In Polish: Nieć, Julian. „Drukarnie na Wołyniu.” Oriens, r. IV (1936): 147-150.]

Ohienko 1995: Ohienko, Ivan (Metropolitan Ilarion). History of the Ukrainian Literary Language. Kiev: Nasha Kultura i Nauka, 1995. [In Ukrainian: Огієнко, Іван (Митрополит Іларіон). Історія української літературної мови. Київ: Наша культура і наука, 1995.]

Ohienko 2011: Ohienko, Ivan (Metropolitan Ilarion). Our literary language. Ed. by Nikolay Timoshik. Kiev: Nasha Kultura i Nauka, 2011. [In Ukrainian: Огієнко, Іван (Митрополит Іларіон). 
Наша літературна мова. Упорядник, автор передмови і коментарів Микола Тимошик. Київ: Наша культура і наука, 2011.]

Plyushch 1962: Plyushch, Pavlo. "On the Question of the So-Called Simple Language of the Seventeenth and Eighteenth Centuries in Ukraine." In Bilodid, I. et al., eds. Questions about the Historical Development of the Ukrainian Language, 27-34. Kharkiv State University Press, 1962. [In Ukrainian: Плющ, Павло. „До питання про так звану просту мову XVI-XVIII ст. на Україні.“ B: Білодід, I. К. et al., ред. Питання історичного розвитку української мови, 27-34. Харьків: Видавництво Харківського державного університету, 1962.]

Pouchenije o svyatyx tajnax 1745: Pouchenije o svyatyx tajnax... Univ, 1745. [In prosta mova: Поученіе о с[вя]тих тайнах... [Uniów], 1745.]

Shevelov 2002: Shevelov, George. Historical Phonology of the Ukrainian Language. Translation from the English Edition of Sergei Vakulenko and Andriy Danilenko (Shevelov, G. Y. A Historical Phonology of the Ukrainian Language. Heidelberg, 1979). Kharkiv: Akta, 2002. [In Ukrainian: Шевельов, Юрій. Історична фонологія української мови. Переклад з англійського видання Сергія Вакуленка та Андрія Даниленка (Shevelov, G. Y. A Historical Phonology of the Ukrainian Language. Heidelberg, 1979). Харків: Акта, 2002.]

Simja slova bozhja 1772: Simja slova bozhja... Pochayiv, 1772. [In prosta mova: Спмяя слова божія... [Poczajów], 1772.]

Slovo k narodu kafolicheskomu 1765: Slovo k narodu kafolicheskomu... Pochayiv, 1765. [In prosta mova: Слово к народу кафолическому... [Poczajów], 1765.]

Sobranije pripadkov 1722: Sobranje prypadkow kratkoje... Suprasl, 1722. [In prosta mova: Собранїе прыпадковъ краткое... [Supraśl], 1722.]

Sobranije pripadkov 1732: Sobranje prypadkow kratkoje... Univ, 1732. [In prosta mova: Собраніе припадков краткое... [Uniów], 1732.]

Strelchuk 1990: Strelchuk, Halina P. "The Inflection System in the Ukrainian Interludes of the XVII-XVIII centuries." Abstract of PhD dissertation. Taras Shevchenko State University of Kyiv, 199o. [In Russian: Стрельчук, Галина П. „Система словоизменения в украинских интермедиях XVII-XVIII вв.“ Автореферат дис. кандидата филологических наук. Киев. гос. ун-т им. Т. Г. Шевченко. Киев, 1990.]

Synod prowincjalny 1785: The Provincial Ruthenian Synod in Zamosc, 1720. Vilnius, 1785. [In Polish: Synod prowincjalny ruski w Zamościu roku 1720 odprawiony. Wilno, 1785.]

Temcinas 2017: Temcinas, Sergey. "Languages of the Ruthenian Culture in the First Polish Republic." In Kuczynska, Malgorzata, ed. Between East and West. Orthodoxy and the Union, 81-120. Warsaw University Press, 2017. [In Polish: Temčinas, Siergiejus. „Języki kultury ruskiej w Pierwszej Rzeczypospolitej." W: Kuczyńska, M., red. Między Wschodem a Zachodem. Prawosławie i unia, 81-120. Warszawa: Wyd. UW, 2017.]

Uspenskij 1994: Uspenskij, Boris. A brief Essay on the History of the Russian Language (XI-XIX centuries). Moscow: Gnozis, 1994. [In Russian: Успенский, Борис. Краткий очерк истории русского языка (XI-XIX вв.). Москва: Гнозис, 1994.] 